\title{
STUDI KINETIKA EKSTRAK DAUN JAMBU BIJI SEBAGAI OBAT PENYEMBUH DIARE
}

\author{
MASNI RAHMAYANTI GAJA8 ${ }^{* 1}$ \\ ${ }^{1}$ Pendidikan Kimia,FMIPA, Universitas Negeri Padang, Indonesia \\ *E-mail : masnirahmayanti.2000@gmail.com
}

\begin{abstract}
ABSTRAK. Studi ini bertujuan untik membuat tumbukan daun jambu biji untuk menghilangkan rasa sakit perut atau bisa juga disebut dengan diare. Metode ini dilakukan adalah eksperimen dan uji aktivitas katalitik secara langsung. Tahap pertama di lakukan dengan tumbukan dari daun jambu biji. Uji aktivitas langsung dengan variasi 7 helai 2 sampai 3 kali perhari selama 2 hari. Hasil eksperimen membuktikan bahwa tumbukan daun jambu biji dapat menghilangkan rasa sakit perut atau diare. Kondisi optimum tercapai pada hari ke dua. Penyembuhan ini diduga karena aktivitas katalitik ekstrak mengandung flavonoid dan tanin dalam penyembuhan terhadap usus manusia.
\end{abstract}

Kata kunci : sakit perut, diare, katalitik, aktivitas, daun jambu biji, flavonoid, tanin, usus manusia.

\section{PENDAHULUAN}

Reaksi kimia ${ }^{(1)}$ adalah suatu proses dalam kehidupan sehari-hari yang selalu menghasilkan perubahan. Reaksi kimia ${ }^{(2)}$ dapat terjadi secara cepat dan lambat. Dimana reaksi kimia ${ }^{(3)}$ ada dikehidupan kita. Reaksi ${ }^{(4)}$ sangat 
penting untuk kita. Reaksi kimia ${ }^{(5)}$ terdapat ditubuh kita, terdapat pada hewan maupun tumbuhan. Reaksi kimia yang kita bahas adalah reaksi yang terjadi didalam perut. Dimana yang kita bahas adalah cara mengobati sakit perut atau diare dengan tumbukan daun jambu biji.

Katalis $^{(6)}$ adalah suatu cara untuk mempercepat suatu reaksi. Didalam reaksi kimia sangat di perlukan katalis sebagai pembantu mempercepat reaksi. Yang ingin kita bahas adalah daunjambu biji sebagai katalis. Daun jambu biji digunakan sebagai katalis untuk mempercepat penyembuhan sakit perut atau diare. Ada beberapa diantara kita yang tidak tahu bahwa daun jambu biji dapat menyembuhkan penyakit yang kita alami. Tidak hanya sakit perut yang dapat di obati oleh daun jambu biji. Daun jambu biji juga dapat mengobati sakit yang ada pada kulit kita.

Nah, sakit perut adalah suatu hal yang tidak menyenangkan bagi kita. Sakit perut biasanya diakibatkan oleh beberapa faktor. Yang pertama makanan, yang kedua udara. Mengonsumsi makanan memang menyenangkan, namun kita tidak mengetahui apakah makanan itu baik untuk tubuh kita atau tidak. Dan udara dingin juga adalaah pemicu sakit perut dan diare ${ }^{(7)}$, hal ini menyebabkan kita lemas. Seperti biasanya, kemungkinan beberapa orang langsung membawa ke rumah sakit. Namun disini kita akan membahas sakit perut dapat diobati dengan cara alami atau sering juga disebut herbal.

Daun jambu biji adalah obat alami atau herbal yang dapat mengobati diare atau sakit perut. Daun jambu biji adalah tumbuhan yang sangat mudah kita temukan dimana pun kita berada. Dimana biji jambu biji ini mengandung flavonoid ${ }^{(8)}$, guercetin glycoside dan $\operatorname{tanin}^{(9)}$. Yang dikandung oleh daun jambu biji itulah yang dapat mengobati rasa sakit yang kita rasakan. Tanin, tanin adalah salah satu yang di miliki oleh daun jambu ${ }^{(10)}$. Tanin ${ }^{(11)}$ berfungsi 
untuk mengecilkan pori-pori pada usus . karena adanya taninlah yang dapat membantu menyembuhkan rasa sakit yang kita rasakan.

Akibat pori-pori usus terbukalah sakit perut terjadi. Sakit perut kita ini juga dapat membuat kita lemas karena kehilangan banyak cairan. Nah, disuatu kota di Sumatera Utara tepatnya disidikalang. Disana ada salah satu penduduk yang memakan tumbukan daun jambu biji selama dua hari. Dan setelah dua hari rasa sakit perut yang beliau alami mereda dan bahkan tidak terasa sakit lagi. Jadi, sudah terbukti bahwa daun jambu biji dapat membantu kita dalam penyembuhan sakit perut atau diare.

\section{METODE}

\section{ALAT DAN BAHAN}

A. Alat :

1. Sendok ( Stainless steel )

2. Pisau ( Roch Messer )

3. Gelas (Luminarc Conical)

B. Bahan

1. Daun jambu biji ( Sidikalang, Sumatera Utara)

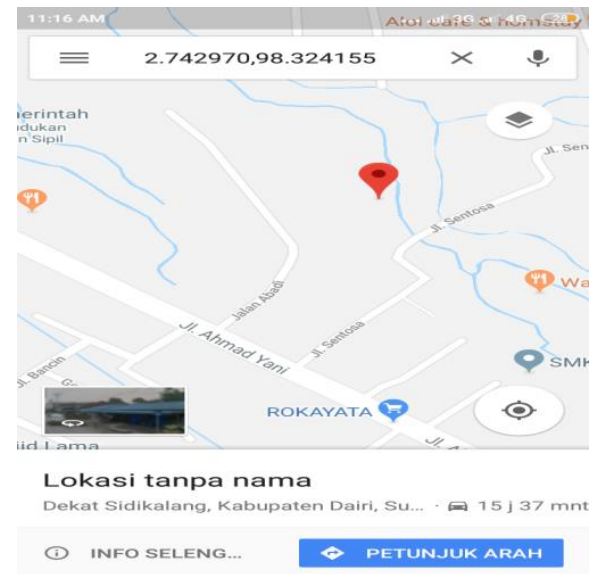


2. Air ( AQUA)

\section{PROSEDUR KERJA}

\section{Penyiapan sampel}

Penyiapan sampel diambil dari lokasi. Pada saat pengambilan diambil 7 helai daun jambu biji. Pembuatan ekstraknya ${ }^{(12)}$ dibuat dengan cara di tumbuk/haluskan daun biji jambu sebanyak 7 helai lalu masukkan aqua hingga halus lalu di saring. Setelah di campurkan tumbukan daun jambu biji $^{(13)}$ tersebut dapat diminum atau di konsumsi. Dalam pengujian ekstrak $^{(14)}$ hasil yang saya dapat langsung dari orang yang bersangkutan. Jadi hal ini adalah obat yang sudah lazim untuk digunakan atau di konsumsi disaat sakit perut atau diare.

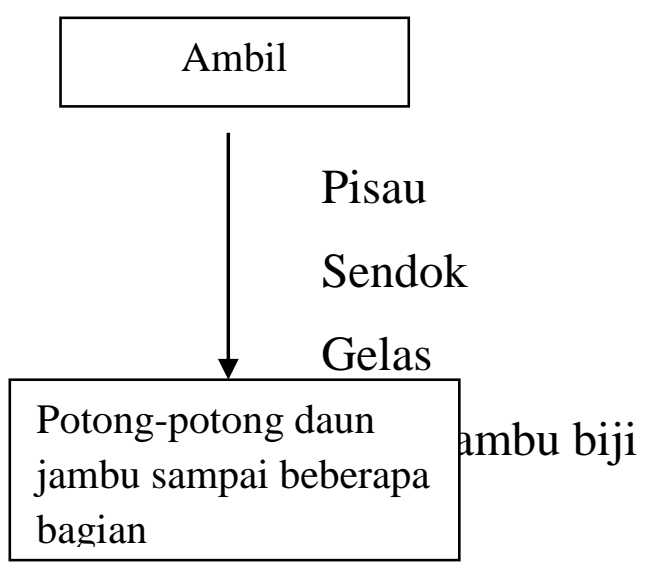




$\mid \begin{array}{r}\text { Haluskan daun jambu } \\ \text { masukkan sedikit aqua } \\ \begin{array}{|l}\text { Daun jambu biji siap di } \\ \text { konnsumsi }\end{array} \\ \hline\end{array}$

\section{PEMBAHASAN HASIL}




\section{Hasil Pembuatan}

Hasil dari pembuatan ekstrak diperoleh dari hasil penyaringan. Dapat kita lihat pada gambar berikut ini :

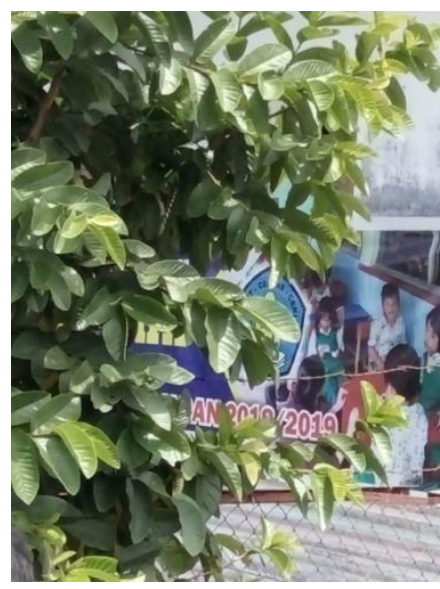

Pohon jambu biji

yang belum di petik

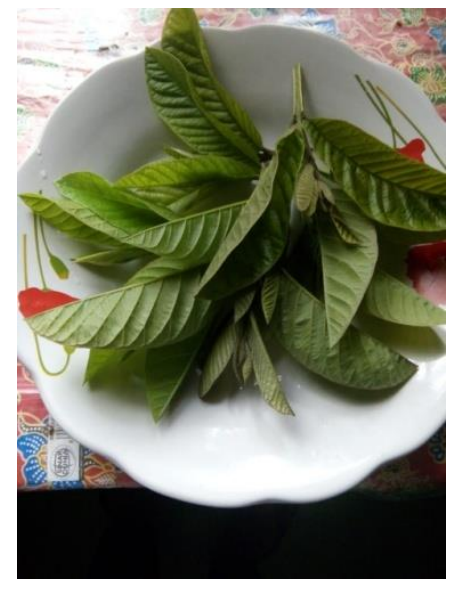

Daun jambu biji yang

telah di petik

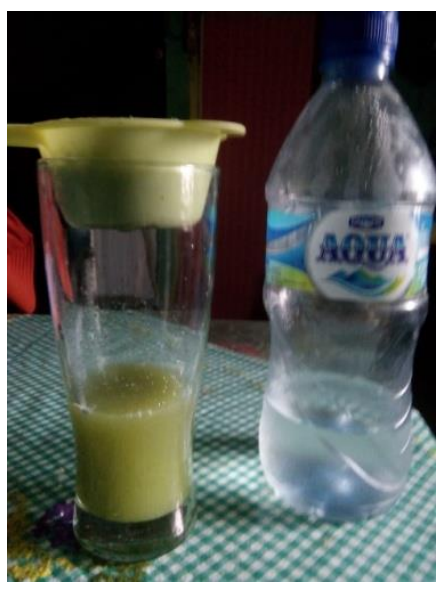

daun jambu biji

telah di saring

Dari hasil uji coba ini, kita lakukan pada salah satu ibu yang tinggal di kabupaten Sidikalang di provinsi Sumatera Utara. Beliau memberikan kebenaran bahwa daun jambu biji sangat berkhasiat dan dapat mengobati sakit perut yang beliau alamai. Sebagaimana pada tabel berikut :

\section{Hasil Uji Coba}

\begin{tabular}{|l|l|}
\hline Pemakaian & Tingkat kesakitan \\
\hline $\begin{array}{l}\text { Peminuman } \\
\text { satu kali daun } \\
\text { jambu biji }\end{array}$ & $\bullet \bullet \bullet \bullet \bullet$ \\
\hline $\begin{array}{l}\text { Peminuman ke } \\
\text { dua kali daun } \\
\text { jambu biji }\end{array}$ & $\bullet \bullet \bullet \bullet$ \\
\hline Peminuman ke & $\bullet \bullet \bullet$ \\
\hline
\end{tabular}

Keterangan :

- adalah tingkat kesakitan yang diderita. 


\begin{tabular}{|l|l|}
\hline $\begin{array}{l}\text { tiga kali daun } \\
\text { jambu biji }\end{array}$ & \\
\hline $\begin{array}{l}\text { Peminuman Ke } \\
\text { empat kali }\end{array}$ & $\bullet \bullet$ \\
daun jambu & \\
biji & \\
\hline $\begin{array}{l}\text { Peminuman ke } \\
\text { lima kali daun } \\
\text { jambu biji }\end{array}$ & $\bullet$ \\
\hline
\end{tabular}

\section{PEMBAHASAN}

Reaksi kimia ${ }^{(15)}$ adalah suatu proses dalam kehidupan yang akan menghasilkan perubahan. Katalis ${ }^{(16)}$ adalah suatu cara untuk mempercepat suatu kerja dari reaksi. Katalis ${ }^{(17)}$ dan reaksi kimia $^{(18)}$ sangat berkaitan erat. Hal tersebut karena reaksi kimia ${ }^{(19)}$ membutuhkan katalis untuk mempercepat reaksi untuk membentuk hal yang baru. Tujuan eksperimen ini adalah untuk menguji katalitik ${ }^{(20)}$. Uji coba ini di lakukan dengan menggunakan daun jambu biji.

Daun jambu biji ${ }^{(21)}$ banyak digunakan dalam penyembuhan terutama pada penyembuhan sakit perut atau diare ${ }^{(22)}$ atau juga dalam penyembuhan kulit. Disini dilakukan uji coba apakah benar daun jambu biji(23) dapat menyembuhkan sakit. Percobaan ini dilakukan dengan cara, ambil pisau, sendok, gelas, dan 7 helai jambu biji. Daun jambu biji ${ }^{(24)}$ ini kita haluskan, guna dihaluskan agar kita mendapat sari pati. Pada saat menghaluskan daun 
jambu biji kita masukkan aqua agar lebih mudah dalam mendapatkan sari patinya.

Selanjutnya, setelah sari patinya kita dapat, kita minum pelan-pelan dengan sendok. Daun jambu biji ini kita minum 2 hari, dalam sehari kita minum 3 kali. Setelah minum sari pati tersebut dapat menurukan dan menghilangkan rasa sakit perut. Kenyataan nya setelah di uji coba hal itu ternyata benar. Hal ini karena ada kandungan zat yang ada dalam daun jambu biji. Namun apabila sakitnya belum sembuh juga kita dapat meneruskannya.

Di dalam daun jambu biji, terdapat tanin, flavonoid ${ }^{(25)}$ dan juga zat guercetin glycoside $^{(26)}$. Terdapatnya tannin ${ }^{(27)}$ ini membuat pori-pori usus ${ }^{(28)}$ tertutup sehingga dalam pembuangan menjadi baik kembali. Didalam daun jambu biji ${ }^{(29)}$ memiliki antibakteri ${ }^{(30)}$ yang bagus dan kuat untuk mencegah bakteri tumbuh diakibatkan diare ${ }^{(31)}$ tersebut. Sehingga daun jambu biji ini baik kita konsumsi saat kita mengalami diare. Hal ini sudah di ujikan oleh salah satu ibu yang ada di Sidikalang, Sumatera Utara. Efek dari daun jambu adalah setiap sekali pemakaian rasa sakit semakin menghilang.

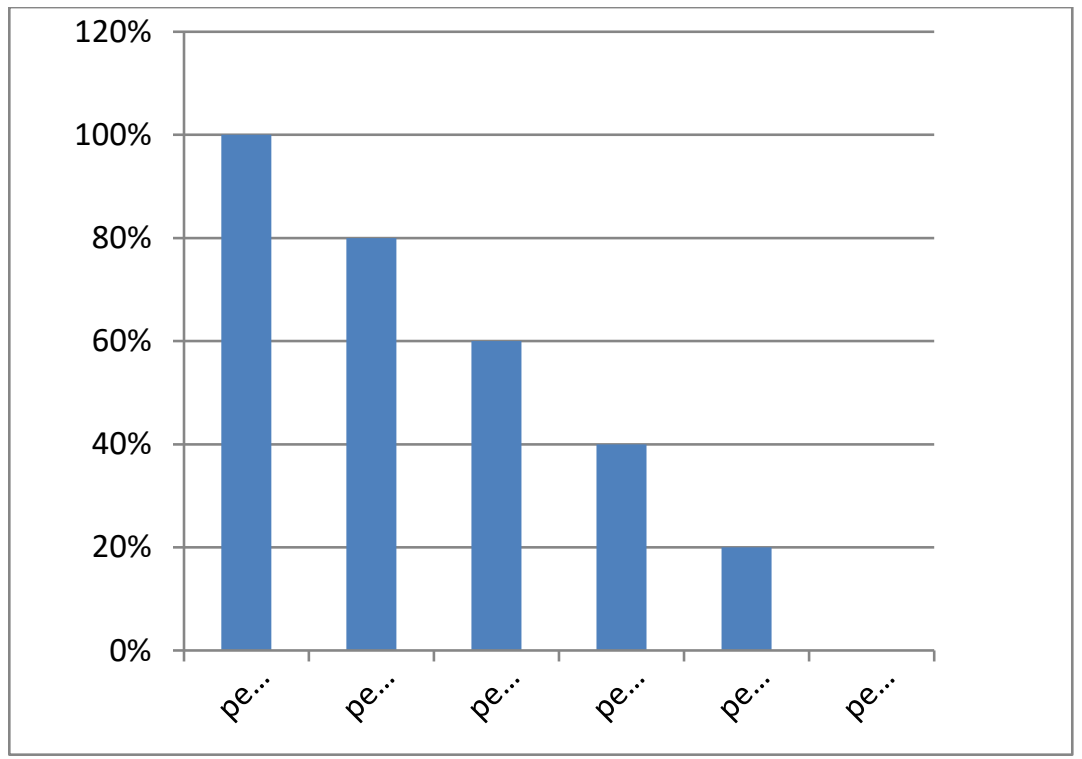




\section{KESIMPULAN}

Ekstrasi $^{(32)}$ dibuat dengan cara tumbukan / menghaluskan daun jambu biji. Ekstraksi ini dapat menyembuhkan diare ${ }^{(33)}$ atau sakit perut. Tetapi bukan hanya itu saja, daun jambu biji ini banyak manfaatnya bagi kehidupan kita. Pemakaian atau peminuman ekstrak daun jambu biji ini biasanya hanya dilakukan enam kali peminuman dalam waktu dua hari. Namun apa bila belum sembuh juga maka dapat kita lanjutkan atau segara bawa ke rumah sakit. Ekstrak daun jambu biji ini mengandung zat flavonoid ${ }^{(34)}$, zat guercetun glycoside ${ }^{(35)}$ serta tanin. Tanin ini lah yang sangat bekerja karena taninlah yang menutup pori-pori yang terbuka di usus.

\section{REFERENSI}

[1]Charlena, Purwaningsih,Henny, Rosdiana,Tina. 2008. PENCIRIAN DAN UJI AKTIVITAS KATALITIK ZEOLIT ALAM TERAKTIVASI. Jurnal Riset Kimia. Vol 1, No 2.

[2]Astiti Asih, I. A. R., Adi Setiawan, I M. 2008. SENYAWA

GOLONGAN FLAVONOID PADA EKSTRAK n-BUTANOL KULIT BATANG BUNGUR (Lagerstroemia speciosa Pers.). Journal of Chemistry. Vol. 2 , No. 2.

[3]Malangngi, Liberty, Sangi, Meiske, Paendong, Jessy . 2012. Penentuan Kandungan Tanin dan Uji Aktivitas Antioksidan Ekstrak Biji Buah Alpukat (Persea americana Mill.). JURNAL MIPA UNSRAT ONLIN. Vol 1, No 1. 
[4]Kusnaryo, Radya Purna Wijaya, Ali Altway,. 2008. ANALISA

TRANSFER MASSA DISERTAI REAKSI KIMIA PADA ABSORPSI CO2. Teknik Kimia. Vol 2, No 2.

[5]Pangumpia, Sri Wahyuni, Gugule, Sanusi, Karundeng, A. Evelin. 2014.

Pembelajaran Paparan Konsep Matematika pada Materi Persamaan Reaksi Kimia di SMA Frater Don Bosco Manado. JSME MIPA UNIMA. Vol 2, No 2.

[6]Darma Santi. 2013. MODIFIKASI ZEOLIT ALAM SEBAGAI KATALIS DAN UJI AKTIVITAS KATALIS DALAM REAKSI HIDRORENGKAH MINYAK KULIT JAMBU METE (ANACARDIUM OCCIDENTALE) MENJADI BIOGASOLINE DAN BIODIESEL.Vol.5, No.2

[7]Amaliah, Siti. 2010. HUBUNGAN SANITASI LINGKUNGAN DAN FAKTOR BUDAYA DENGAN KEJADIAN DIARE PADA ANAK BALITA DI DESA TORIYO KECAMATAN BENDOSARI KABUPATEN SUKOHARJO. PROSIDING SEMINAR NASIONAL. Vol 1, No 1

[8]Sayono, U, Nurullita, M, Suryani. 2010. PENGARUH KONSENTRASI FLAVONOID DALAM EKSTRAK AKAR TUBA (Derris eliptica) TERHADAP KEMATIAN LARVA Aedes aegypti. JURNAL KESEHATAN MASYARAKAT INDONESIA. Vol 6, No 1

[9]DINIATIK, SOEMARDY, EDDY, INDRI, KHANINA. 2007. PERBANDINGAN KADAR FLAVONOID TOTAL DAN TANIN TOTAL PADA TEH HIJAU DAN TEH HITAM Camellia siniensis (L.) O.K. PHARMACY. Vol 5, No 3

[10]Rosidah, Afizia, Wila Mahita. 2012. POTENSI EKSTRAK DAUN JAMBU BIJI SEBAGAI ANTIBAKTERIAL UNTUK MENANGGULANGI SERANGAN BAKTERI AEROMONAS HYDROPHILA PADA IKAN GURAME (Osphronemus Gouramy lacepede). Jurnal Akuatika. Vol 3, No 1 
[11] Febriani, S. S., Yolanda, T., Arianti, V. A., \& Zainul, R. (2018, October 12). A Review Solid Stated : Principles and Methode. https://doi.org/10.31227/osf.io/7us4x

[12] Febriani, S. S., Yolanda, T., Arianti, V. A., \& Zainul, R. (2018, October 12). A Review Solid Stated : Principles and Methode. https://doi.org/10.31227/osf.io/7us4x

[13] Dinata, A. A., Rosyadi, A. M., Hamid, S., \& Zainul, R. (2018, October 15). A Review CHEMICAL VAPOR DEPOSITION : PROCESS AND APPLICATION. https://doi.org/10.31227/osf.io/yfeau

[14] Syafei, N. (2018) "Riset Material ANALISA FENOMENA KOROSI PELAT PIPA BAJA KARBON API 5L-X65 DALAM LARUTAN 7900 ML AIR LAUT DAN 100 ML AMONIAK PADA KONDISI GAS CO2 DAN H2S JENUH PADA SUHU RUANG.", EKSAKTA: Berkala Ilmiah Bidang MIPA, 19(1), pp. 7-13. doi: 10.24036/eksakta/vol19-iss1/83

[15] Zainul, R., \& Prima, C. B. (2018, December 9). TEKNOLOGI MATERIAL MAJU Prinsip Dasar dan Aspek Rekayasa. https://doi.org/10.31227/osf.io/p63wc

[16] M., Sanjaya, H., \& Zainul, R. (2018, August 11). Characterization of napa soil and adsorption of $\mathrm{Pb}$ (II) from aqueous solutions using on column method. https://doi.org/10.31227/osf.io/t8fh9

[17] Liza, Y. M., Yasin, R. C., Maidani, S. S., \& Zainul, R. (2018, October 9). SOL GEL : PRINCIPLE AND TECHNIQUE (A REVIEW). https://doi.org/10.31227/osf.io/2cuh8

[18] Chairi, I., E., \& Zainul, R. (2018, September 19). Pengembangan LKS dengan Pendekatan Saintifik Berbasis Discovery Learning Pada Materi Hukum Dasar Kimia untuk Pembelajaran Kelas X SMA/MA. https://doi.org/10.31227/osf.io/xnbtv

[19] Zainul, R. (2018, August 16). Design and Modification of Copper Oxide Electrodes for Improving Conversion Coefficient Indoors Lights (PV-Cell) Photocells. https://doi.org/10.31227/osf.io/pgn84

[20] Hidayani, T. (2018) "GRAFTING POLIPROPILENA DENGAN MALEAT ANHIDRIDA SEBAGAI PENGIKAT SILANG DENGAN 
INISIATOR BENZOIL PEROKSIDA", EKSAKTA: Berkala Ilmiah Bidang MIPA, 19(1), pp. 56-62. doi: 10.24036/eksakta/vol19-iss1/127

[21] Joebaedi, K. (2018) "MODEL STAR(1;1) PADA DATA PRODUKTIVITAS TEH”, EKSAKTA: Berkala Ilmiah Bidang MIPA, 19(1), pp. 35-38. doi: 10.24036/eksakta/vol19-iss1/118.

[22] Dinata, M. and Soehardi, F. (2018) "Factor Analysis of Physics Chemistry Waters that Affects Damage Safety Cliff on the Outskirts of River Siak", EKSAKTA: Berkala Ilmiah Bidang MIPA, 19(2), pp. 4649. doi: 10.24036/eksakta/vol19-iss2/143.

[23] Horiza, H., Azhar, M. and Efendi, J. (2017) "EKSTRAKSI DAN KARAKTERISASI INULIN DARI UMBI DAHLIA (Dahlia sp.L) SEGAR DAN DISIMPAN", EKSAKTA: Berkala Ilmiah Bidang MIPA, 18(01), pp. 31-39. doi: 10.24036/eksakta/vol18-iss01/14.

[24] Sari, A. (2017) "POTENSI ANTIOKSIDAN ALAMI PADA EKSTRAK DAUN JAMBLANG (Syzigium cumini (L.) Skeels)", EKSAKTA: Berkala Ilmiah Bidang MIPA, 18(02), pp. 107112. doi: 10.24036/eksakta/vol18-iss02/61.

[25] Sumarmin, R. (2018) "Pengaruh Ekstrak Kulit Buah Manggis (Garcinia mangostana L.) terhadap Histologis Pankreas Mencit (Mus musculus L. Swiss Webster) yang Diinduksi Sukrosa", EKSAKTA: Berkala Ilmiah Bidang MIPA, 19(1), pp. 100-112. doi: 10.24036/eksakta/vol19iss $1 / 123$.

[26] Rizki Saputra, M. and Sumarmin, R. (2018) "PENGARUH EKSTRAK DAUN SIRIH MERAH (Piper crocatum Ruiz \& Pav.) TERHADAP GLUKOSA DARAH MENCIT (Mus musculus L.) JANTAN YANG DIINDUKSI SUKROSA", EKSAKTA: Berkala Ilmiah Bidang MIPA, 19(1), pp. 43-55. doi: 10.24036/eksakta/vol19-iss1/124.

[27] Sanjaya, H. (2017) "DEGRADASI METHYLENE BLUE MENGGUNAKAN KATALIS ZnO-PEG DENGAN METODE FOTOSONOLISIS”, EKSAKTA: Berkala Ilmiah Bidang MIPA, 18(02), pp. 21-29. doi: 10.24036/eksakta/vol18-iss02/45.

[28] Iskandar, I., Horiza, H. and Fauzi, N. (2017) "EFEKTIVITAS BUBUK BIJI PEPAYA (Carica Papaya Linnaeaus) SEBAGAI LARVASIDA 
ALAMI TERHADAP KEMATIAN LARVA AEDES AEGYPTY

TAHUN 2015", EKSAKTA: Berkala Ilmiah Bidang MIPA, 18(01), pp.

12-18. doi: 10.24036/eksakta/vol18-iss01/12

[29] Prabowo, H. (2018) "PENYELIDIKAN KELAYAKAN KIMIA DAN PENYEBARAN CADANGAN PASIR BESI DAERAH TIKU

KABUPATEN AGAM UNTUK BAHAN BAKU SEMEN PADA PT. SEMEN PADANG", EKSAKTA: Berkala Ilmiah Bidang MIPA, 19(1), pp. 39-42. doi: 10.24036/eksakta/vol19-iss1/121.

[30] Parbuntari, H., Prestica, Y., Gunawan, R., Nurman, M. and Adella, F. (2018) "Preliminary Phytochemical Screening (Qualitative Analysis) of Cacao Leaves (Theobroma cacao L.)", EKSAKTA: Berkala Ilmiah Bidang MIPA, 19(2), pp. 40-45. doi: 10.24036/eksakta/vol19-iss2/142.

[31] Ruswandi, R. (2018) "Determination of Fructose Content resulted by Inulin Hydrolysis with DNS as Oxidizer", EKSAKTA: Berkala Ilmiah Bidang MIPA, 19(1), pp. 14-23. doi: 10.24036/eksakta/vol19iss $1 / 102.2018$.

[32] Yanuar, F., Tillah, M. and Devianto, D. (2018) "Modeling of Human Development Index Using Ridge Regression Method", EKSAKTA: Berkala Ilmiah Bidang MIPA, 19(2), pp. 1-11. doi: 10.24036/eksakta/vol19-iss2/134

[33] Ningsih, S. K. (2017) "SINTESIS DAN KARAKTERISASI NANOPARTIKEL ZnO DOPED Cu2+ MELALUI METODA SOLGEL”, EKSAKTA: Berkala Ilmiah Bidang MIPA, 18(02), pp. 39-51. doi: 10.24036/eksakta/vol18-iss02/51

[34] Syafei, N., Hidayat, D., Emilliano, E. and Men, L. (2018) “Analysis Cracking Corrosion on Carbon Steel Pipes API 5L-X65 In Solution $7700 \mathrm{ml}$ Aquades, $250 \mathrm{ml}$ Acetic Acid and $50 \mathrm{ml}$ Ammonia with Gas $\mathrm{CO} 2$ and H2S in Saturation Condition", EKSAKTA: Berkala Ilmiah Bidang MIPA, 19(2), pp. 21-31. doi: 10.24036/eksakta/vol19iss2/138

[35] Setianto, S. (2017) “ANALISA KUANTITATIF CAMPURAN SENYAWA OKSIDA SEBAGAI DASAR IDENTIFIKASI KANDUNGAN BAHAN SUMBER DAYA ALAM Studi Kasus : Kandungan Mineral pada Pasir Besi di Pesisir Pantai Selatan, Jawa 
Barat", EKSAKTA: Berkala Ilmiah Bidang MIPA, 18(02), pp. 173-177. doi: 10.24036/eksakta/vol18-iss02/74 